\title{
Application of statistical linear elastic fracture mechanics to pressure vessel reliability analysis
}

Becher, P.E.; Pedersen, Arne

Publication date:

1973

Document Version

Publisher's PDF, also known as Version of record

Link back to DTU Orbit

Citation (APA):

Becher, P. E., \& Pedersen, A. (1973). Application of statistical linear elastic fracture mechanics to pressure vessel reliability analysis. Risø National Laboratory. Risø-M No. 1650

\section{General rights}

Copyright and moral rights for the publications made accessible in the public portal are retained by the authors and/or other copyright owners and it is a condition of accessing publications that users recognise and abide by the legal requirements associated with these rights.

- Users may download and print one copy of any publication from the public portal for the purpose of private study or research.

- You may not further distribute the material or use it for any profit-making activity or commercial gain

- You may freely distribute the URL identifying the publication in the public portal

If you believe that this document breaches copyright please contact us providing details, and we will remove access to the work immediately and investigate your claim 
Application of Statisticai Lincar El titio Fracture

Department or group

Meshaniss to Presidure Vousel Reliability Altalysia

Reactor

ky

P.E. Becher and Arne Pedersen

Group's own registration number(s)

$25-3-17$

13 pages $+\quad$ tables +16 illustrations

\section{Abstract}

An evaluation of the failure probability for a pressure vessel is made on the basis of LEFM (Linear Elastic Fracture Mechanics). Failure is identified by actual crack length (i.e. stress intensity factor $\mathrm{K}_{\mathrm{I}}$ ) equa: zitical crack length (i.e. plain strain fracture toughness $\mathrm{K}_{\mathrm{IC}}$ ).

The probability of failure is the joint probability that there exists a crack ( $i . e . K_{I}$ ) greater than a given crack (i.e. K) and that the critical crack (i.e.kIC) is smaller than that same crack, where $K_{I}$ and $K_{I C}$ are considered for same time and location. $K_{I C}$ as well as $K_{I}$ are treated as statistical variables with probability density functions, which are functions of material, initial cracks, stresses and crack growth.

The integrated calculations of failure probability are performed by a computer program utilizing the Monte Carlo method with importance sampling.

Available on request from the Library of the Danish Atomic Energy Commission (Atomener gikommissionens Bibliotek), Risø, Roskilde, Denmark. Telephone: (03) 355101 , ext. 334, telex: 5072 . 


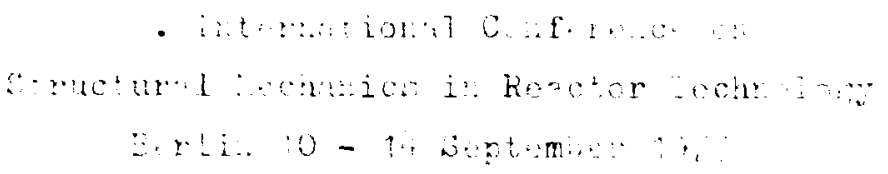

APPLICATION OF STATISTICAL LINEAR ELASTIC FRACTURE
MECHANICS TO PRESSURE VESSEL RELIABILITY ANALYSIS

P.E. BECHER, A. PEDERSEN

Danish Aromic Energy Commission,

Reactor Engineering Department, Research Establishment Rise, DK-4000 Roskilde, Denmark

\section{SUMMARY}

An evaluation of the failure probability for a pressure vessel is made on the basis of LEFM (Linear Elastic Fracture Mechanics). Failure is identified by actual crack length equal critical crack length.

The probability of failure is the joint probability that there exists a crack (i.e. $K_{1}$ ) greater than a given crack (i.e. $\boldsymbol{K}$ ) and that the critical crack (i.e. $\boldsymbol{K}_{I C}$ ) is smaller than that same crack, where $K_{I}$ and $K_{I C}$ are considered for same tire and location.

$K_{I C}$ as well as $K_{J}$ are treated as statistical variables with probability density functions (p.d.f.), which are functions of material, location and time.

The variability of $K_{I C}$ (that is the p.d.f. of $K_{I C}$ ) is a result primarily of the statistical nature of the material properties and to a lesser degree of the increasing neutron-dose experienced by certain parts of the pressure vessel.

The variability of $K_{J}$ (that is the p.d.f. of $K_{J}$ ) is a result of the following paraneters

(1) Initial distribution of cracks (that is the crack distribution at the start-up of the reactor) regarded as a statistical variable, because of the uncertainty in the non-destructive testing of the pressure vessel prior to start-up.

(2) Stresses, regarded as a statistical variable because of the uncertainty in the stress analysis and the geometry of the vessel.

(3) Crack growth by fatigue, which is a result of the normal (with probability equal to 1.0) and abnormal (with a p.d.f.) operational transients. The statistical nature of the crack growth is due to the statistical variation of the abnormal operational transients.

(4) Material properties (that is $K_{I C}$, yield strength and the factors governing the fatigue crack growth) regarded as statistical variables.

The p.d.f.'s of the above mentioned parameters are evaluated on basis of available literature. The integrated calculations of failure probability are performed by a computer program utilizing the Monte Carlo technique with importance sampling, which gives a greater freedom in selection of p.d.f.'s. The influence of periodic in service inspection on the failure probability is considered. Calculations of failure probability on existing reactors are presented. 
i. Inthonomitom

Failure probabilities of ruator presisure vessels have beer devoted considerable attenition during the last years. Many efiorts have been made to translate statistical eviderce of conventional high pressure vessel iritegrity and results of surveillance testing into failure probabilities of nuclear pressure vessels. Both in UK and in Germany suci investigations on vessels comparable with nuclear vessels were conducted (ref. 1 and 2) covering a total of approximately 100.000 and 1.000 .000 vessel years respectively. The total number of failures relevant for nuclear vessel services correspond to failure rates of $10^{-3}-10^{-4}$ per year and catastrophic failure rates of $2 \times 10^{-5}$ per year in the UK investigations, $3 \times 10^{-6}$ per year in the German ones.

Another approach to evaluation of pressure vessel failure probabilities has developed from the increasing application of reliability engineering methods in the aircraft and sateilite design. Most of these applications are concerned with reliability calculations of integrated system performance from knowledge of failure statistics of the different components in the systems. However, the methodology is applicable also to calculations of the probability that a given failure mode for a specific component is exceeded when the variations of the associated design parameters are known.

Examples of such calculations on pressure vessels are given in ref. 3. In these cases the failure criterium is related to either the yield strength or the 17 timate tensile strength of the construction material neglecting possible defects. In the first case the failure criterium is hardly to be considered as a failure, in fact yielding is accepted for certain loading conditions and in certain areas of the vessel. In the second case the failure probability calculated is bound to be extremely low.

A more advanced example in which defects and crack growth are considered is presented in connection with the pipe rupture 
study performed by the General Electric Company (rof. 4). This study makes an estimate of pipe reliability by "the dictribution of time to damage method" (ref. 5). Using Monte Carlo technique with importance sampling, the method gives the probability that cracks grow through the wall of a cylindrical pipe in a chosen time period due to low cycle fatieue. All parameters are regarded as distributed variables, each with separate distribution functions. The failure probability calculated by this method seems to be in better agreement with practical failure experience.

\section{FAILURE MODEL}

In calculations of the reliability of a nuclear pressure vessel on a fully probabilistic basis, all the variables used in the calculations should be regarded as statistical variables each with their own probability distribution (p.d.) function. The number and nature of the parameters are governed by the particular fajluremode to be examined. Furthermore the time-dependency of every parameter has to be evaluated, in order to give "probability of failure" as a function of time.

In this piper the type of pressure vessel failure considered has been restricted to gross failures of the vessel in excess of the type of failures considered as design basis for engineered safeguards such as containment and emergency core cooling.

The only available method considered to give a realistic description of that type of catastrophic failure is the Linear Elastic Fracture Mechanics theory (IEFM). In brief, the theory suggests that gross failure occurs when the stress intensity factor around a cracks with a depth "a" in a nominal stress field S exceede the plain strain fracture toughness $K_{I C}$, i.e. when

$$
K_{I}=S \cdot \sqrt{M \cdot a} \geqq K_{I C}
$$

where

$M$ is a constant which depend upon the type of load and the geometry of the crack. 
The probability that cracks of different siaes exist in the vessel, the uncertainty about the real stress field and in principle also the variation in the constant $M$ due to different crack geometries are combined into a probability distribution function for the stress intensity factor, $K_{I}$. These values of $K_{I}$ are compared with the variation in the fracture toughness $K_{I C}$ giving the probability of failur as:

$$
\text { Prob. of failure }=\text { Probability }\left(K_{I} \geqq K^{x} \text { and } K_{I C} \leqq K^{x}\right)
$$

where

$$
K^{x} \text { assumes all values } 0<K^{x}<\infty \text { (see fig. 1). }
$$

Tn this first application of the method a few simp?ifications have been introduced.

In calculating the time dependency of the probability of failure, the only contribution considered is crack growth by low cycle fatigue. The crack distribution function is thus the only parameter which is assumed to vary with time. The variation is determined on basis of the initial distribution of cracks, the stmess transients and the parameters governing low cycle fatigue. The most important limi ation is that degradation of material properties from neutron irradiation is neglected. This will normally be true for most boiling water reactors while the phenomena probably should be included in calculations on pressurized water reactors.

Further only the cylindrical part of the vessel free from structural discontinuities is treated so far. Admittedly che nozzle and flange areas of the vessel, subject to higher stresses and more sovere stress cycles, are the more questionable parts of the vessel. File IFFM theory, however, is not direct applicable in these circumstances when the stresses approach the yield stress - at best the theory represents a conservative approach in tris case and very high values of failure probabilities which is calculated on this basis might be acceptable.

Finally, the geometry of the cracks considered has been idealized. They are all considered to be semi-elliptic surface 


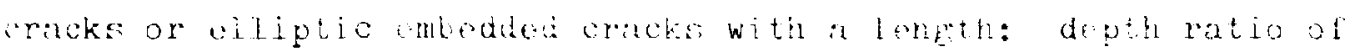

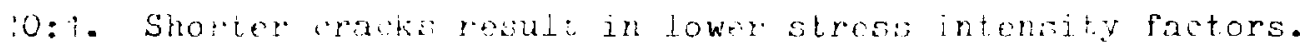

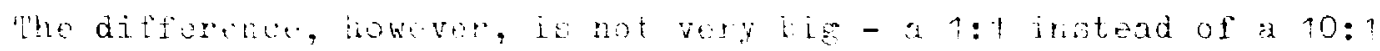

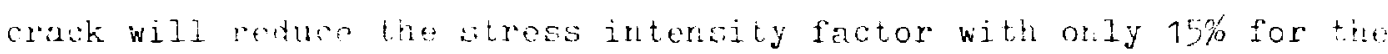
same crack depth.

Beside these simplifications which may be deleted without greater difficulty it luas been recessary to introduce an approximation of a more fundamental nature due to difficulties in measurine the plain strain fractire toughress $\mathrm{K}_{I C}$ at temperatures of above 10 - $20^{\circ} \mathrm{C}$. These difficulties are directly connected to the discussion about the validity of the LEFM concept in tine tough region at elevated temperatures. However, Corten and Sailor (ref.6) has suggested that the plain strain fracture toughness above the transition temperature may be calculated on hasis of the upper shelf Charpy-V, $C_{V}$, fracture toughness and the yield strength, $S_{Y}$, at the temperature in question as:

$$
K_{I C}=\sqrt{5\left(C_{V} S_{Y}-0.05 S_{Y}^{2}\right.}
$$

The distribution function of $K_{I C}$ is thus readily calculated from the distribution functions of $\mathrm{C}_{V}$ and $\mathrm{S}_{\mathrm{Y}}$.

A survey of the relations between the different parameters used in the calculations and the resulting failure probability are shown in fig. 2 .

In order to carry out such calculations in which different types of distribution functions obviously exist, Monte Carlo technique (simulation) is the only possible solution. Fowever, since the failure probability expected is in the order of $10^{-6}$ the number of Monte Carlo trials would be in the order of $10^{8}-10^{9}$ if a reasonable small error should be obtained. With a typical computer time of $10^{-2}$ sec/trial direct simulation becomes impossible and importance sampling is just as necessary a feature as the Monte Carlo technique itself.

As indicated in fig. 2 the calculations are performed in two steps by computer programs named PFM 690 and PFM 683 respectively. Separate block diagrams for the two programs are shown at fig. 3 and 4. 
PFM 690 calculates the crack frowth as a function of time on basis of an initial crack distribution (or a single crack of a given length), crack growth characteristics and stress transients. Resulting crack distributions after different intervals of operation are supplied in the form of histograme.

PFM 683 calculates the probability of failure from a given set of distribution functions for cracks, stresses, yield strength and Charpy-V fracture toughness. The result is thus the probability of failure wher the vessel is loaded with the stresses used in the calculations. Performing such calculations at different intervals of operation with the relevant crack and material data distribution functions, failure probability as function of time may be calculated. The program may also supply histograms of the resuliing $f\left(K_{I}\right)$ and $\mathrm{f}\left(\mathrm{K}_{\mathrm{IC}}\right)$.

PFM 690 uses direct Monte Carlo simulation while PFM 683 uses Monte Carlo simulation with importance sampling. The probability distribution functions may be supplied either in the form of a table $x, f(x)$ or as a Weibull function given by the three constants $m, k$ and $\mathbf{x}_{0}$. The importance sampling is accomplished by Weibull functions as weighting functions supplied as another set of constants.

\section{DISTRIBUTION FUNCTIONS \\ OF INPUT PARAMETERS}

\subsection{Initial cracks}

The existence of cracks in a vessel when it is taken into operation after initial testing and control depends upon many different factors such as fabrication techniques, non-destructive testing methods and requirements, reliability of the methods and the operators, etc. The general appearance of the crack distribution function is expected to be an exponential distribution with . respect to crack size. Small cracks with a depth in the order of 1 - $2 \mathrm{~mm}$ exist almost for sure while the probability that bigger 
cracks will not be detected decreases sharply with the crack size. Defects in the orcier of $10 \%$ of the wall thickness of the vessel i.e. typically $10-20 \mathrm{~mm}$ in depth should be readily detectable. Nevertheless vessels do fail now and then wue to urrevealed big cracks approaching critical crack sizes. In ref. 8 Jordan and 0 'Neil suggest that the probability of missing a potential dangerous defect by ultrasonic testing is somewhere between 1 and $10^{-2}$. Under the impression of these indications the crack distribution function shown at fig. 5 was chosen. The probability that a crack with a depth of $2 \mathrm{~cm}$ will not be detected was specified to $10^{-1}$.

\subsection{Crack growth characteristics}

Crack growth data are normally expressed in terms of the cyclic range of the stress intensity factor $\Delta K_{I}$. Fig. 6 shows a logaritmic diagram of the generalized fatigue crack growth rate law:

$$
\frac{d a}{d N}=C_{0} \Delta K^{n}
$$

For a given $\Delta K$ the variation in measurements of the crack growth rate may be expressed as a probability distribution function $f(d a / d N)$. In the calculations the distribution function is considered to be normal in the logaritmic scale and the same function is used for all $\Delta K$.

Crack growth data on the pressure vessel steel A533B published from the HSST program are combined in fig. 7 . The data represent measurements on different types of material (base plate, heat affected zone and electro slag weld material) and in different environments (BWR, PWR and air). From fig. 7 the constants in the crack growth equation and standard deviation of the normal distributior. function are evaluated.

\subsection{Stress transients}

A typical set of reactor operating transients used to evaluate fatigue ilfe of the pressure vessel in a BWR is reproduced from a safety analysis report (ref. 10) in fig. 8. The number of tran- 
sients indicated are considered to be the most probable number of occurrences.

The effects of these transients in terms of imposed stress cycles on the cylindrical part of the vessel has been evaluated.

Some of the transients are connected to normal operation of the plant, e.g. start up, shut down, pressure tests etc. and may be considered to occur with a given frequency characterized by a period of not more than one year.

The other transients are connected to incidents and other abnormal everts with an occurrence which is statistical by nature. Average numbers of the different abnormal transients may be derived from practical operitional experience and they are considered to occur evenly distrituted over the lifetime of the plant.

The operating history of the plant has therefore been divided into periods of one year such that the combination of transients is the same in each cne year period. The average numbers per year for the different transients used in the calculations are specified in the table fig. 9 together with the corresponding stress cycles.

Since the number cf abnormal transients are statistical figures it is necessary to evaluate the probability that different numbers of a particular transient occur in the one year period. A binomial distribution function may be used to calculate these probabilities if the period is divided into so many intervals that not more than one transient of the type considered can occur in each interval.

In the calculations intervals of one month are used. With the probability of occurence $p$ in each single interval being equal to the average number of transients per month, the probability distribution function with respect to the number of occurrences in one year will be (ref. 7):

$$
f(x)=\left(\begin{array}{l}
12 \\
x
\end{array}\right) p^{x}(1-p)^{12-x}
$$

where

$$
x=0,1, \ldots \ldots 12 \text {. }
$$




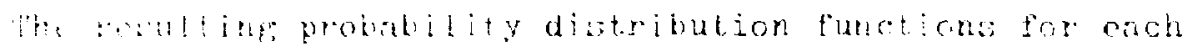

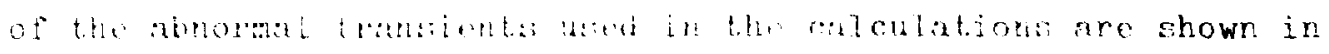
sin. 10 .

3.4 Stresses

In order to calculate the failure probability in a specific operating situation, the stress distribution function should describe the real stress condition in the area of the vessel considered. Calcliation of the stresses in the plain cylindrical part of the vessel can be done very accurate - the real stresses, however, may be different.

Residual stresses from weliing may be considerable but also deviations in geometry, in the elastic modulus of the material etc. may influence the real stresses. For the material considered the allowable calculated stress in normal and upset operation is 26,7 KSI $\left(18,7 \mathrm{~kg} / \mathrm{mm}^{2}\right)$ according to the ASME III code for nuclear pressure vessels. Residual stresses up to $8 \mathrm{KSI}\left(5,6 \mathrm{~kg} / \mathrm{mm}^{2}\right)$ may be present according to ref. 9. The esidual stresses are considered to exist equally probable as tensile and compression. The resulting real stresses in the vessel cylinder may thus vary from approx. $18 \mathrm{KSI}\left(12,7 \mathrm{~kg} / \mathrm{mm}^{2}\right)$ to $34 \mathrm{KSI}\left(23,9 \mathrm{~kg} / \mathrm{mm}^{2}\right)$ with a distribution function as shown at fig. 11. This stress level exists in the vessel cylinder during start up and shut down of the plant and in the rather frequent abnormal situations in which the pressure approach the saf.iv valve set point.

If other pressure vessel codes were used in which allowable stresses are related solely to the yield strength of the material the calculated stress level in the example considered would have been $28,5 \mathrm{KSI}\left(20 \mathrm{~kg} / \mathrm{mm}^{2}\right)$ instead of $26, \% \mathrm{KSI}$ and the stress distribution curve moved to correspoudingly higher stresses.

A special situation which might be interesting to consider is the p re-operational pressure test of the vessel. Most pressure vesscl codes require test pressures which result in stress levels in the cylindrical part of a typical reactor pressure vessel of 33 $\operatorname{KSI}\left(23,1 \mathrm{~kg} / \mathrm{mm}^{2}\right)$.

The yield strength distribution function is also shown in 1 is. 19. 


\subsection{Yield strength and Charpy-V toughness}

Published data from the HSST program on pressure vessel steel plate A533-B have been used to evaluate frequency distribution curves for the yield strength and the Charpy- $V$ toughness. Only lest specimens from tho inner half of the plate were included in order to eleminate the variation in material properties due to the location within the plate. The distribucior functions were fitted to Weibuli distribution functions in order to allow a specific lower limit of the material properties to be introduced. The actual distribution functions are shown at fig. 12 and 13. The lowest possible values in the distribution functions chosen are 60 ftib and $35 \mathrm{KS \perp}$ for the Charpy-V toughness and the yield strenth respectively. These lower limits compare very well with the code requirements of a minimum yield strength of 42,7 KSI and a minimum charpy-V toughness of $50 \mathrm{ftlb}$ based upon measurements from rather few specimens.

\section{RESULTS}

On basis of the distribution functions discussed above calculations of crack growth, crack distribution functions and failure probabilitios at different intervals of operation have been performed.

The calculated crack growth proved to be rather small even for the bigger cracks. In order to obtain a sufficient accurate calculation of the change of the crack distribution function with time very long computer times would therefore be required. Therefore an indirect method for evaluation of the changes of the crack distribution function with time were introduced.

Distribution functions for single cracks are much easier to calculate. Results for 1", 2" and $3^{\prime \prime}$ cracks are shown in fig. 14. Most probable and maximum expected growth of the different crack. sizes are easily recognized. For the biggest crack considered ( $3^{\prime \prime}$ depth) it appears that the growth after 40 years of operation is 
in the order of $1 / 10 "$. From these figures the most probable and maximum expected changes of the initial crack distribution function after 10 and 40 years of operation are evaluated as shown in fig. 15. Only failure prohabilities corresponding to maximum expected crack distribution functions are included.

Results from the failure probability calculations are shown in the table fig. 16. It appears that a nominal stress of $26 \mathrm{KSI}$ $\left(18,3 \mathrm{~kg} / \mathrm{mm}^{2}\right)$ gives a prubability of failure of app. $10^{-8}$ in the beginning of the vessel life. Such stress levels exist during normal heat up and cool in the cylindrical part of a reactor vessel designed in accordance with the ASME III code. An increase of the nominal stress with app. 10\%, which would be allowable according to the DIN code with the material considered, increases the failure probability with a factor of ?. Even higher stresses are allowed during pre-operational hydrostatic testing, typical 25\% higher than the stresses during rormal operation. The resulting failure probability is app. $2 \times 10^{-6}$, i.e. an increase with a factor of 200 .

Further it is seen that the failure probability remains almost constant with time. This means, that the contribution from crack growth to the time dependency of the failure probability is insignificant. Our calculations thus imply that most catastrophic failures occur during hydrostatic testing before the vessel is taken into operation. An estimate of the failure probability per vessel year, as it is normally given, would be $5 \times 10^{-8}\left(2 \times 10^{-6} /\right.$ 40).

Practical failure experience seems to be inconsistent with these results. To explain these differencies it should be recalled that deterioration of material properties with time is neglected and that only crack growth by low cycle fatigue is considered. Other possibilities such as corrosion fatigue and stress corrosion are not included. Further the stress cycles in the cylindrical part of the vessel are actually modest. In other parts of the vessel sspeically in some of the nozzles the stress cycles are more severe both in terms of frequency and stress range. Finally 
recent crack growth rate data published from the HSST program

(ref. 11) indicate that crack growth rates may increase considerably if the load cycling is carried out at lower frequencies tnan normally used, i.e. at frequencies more representative of the load cycles in a reactor pressure vessel.

These limitations in the calculations carried out so far imply that specific figurcs of failurc probabilities calcuialed should be somewhat lower than figures from practical statistical experience.

Further development of the method will include establishment of more accurate distribution functions, inclusion of other factors contributing to time dependency and application of the method to other parts of the vessel.

\section{ACKNOWLEDGEMENT}

The adaption of the Monte Carlo technique into the computer program has been performed by Mr. H.E. Kongs for which we are deeply indebted. 
REFEHFINES

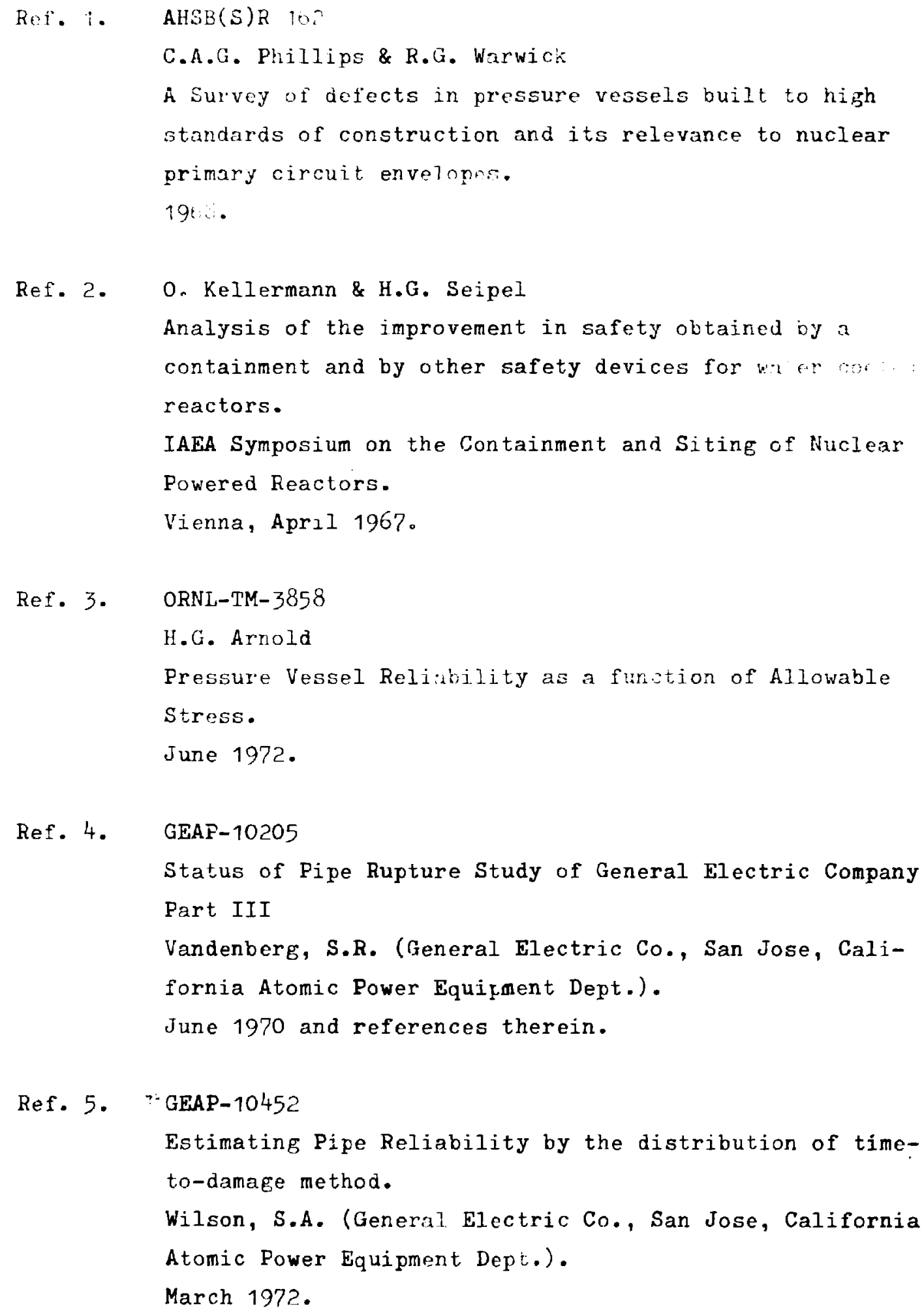

IAEA Symposium on the Containment and Siting of Nuclear Powered Reactors.

Vienna, April 1967.

Ref. 3. ORNL-TM-3858

H.G. Arrold

Pressure Vessel Relidbility as a function of Allowable

Stress.

June 1972 .

Ref. 4. GEAP-10205

Status of Pipe Rupture Study of General Electric Company Part III

Vandenberg, S.R. (General Electric Co., San Jose, California Atomic Power Equirment Dept.).

June 1970 and references therein.

Ref. 5. :GEAP-10452

Estimating Pipe Reliability by the distribution of timeto-damage method.

Wilson, S.A. (General Electric Co., San Jose, California Atomic Power Equipment Dept.).

March 1972. 


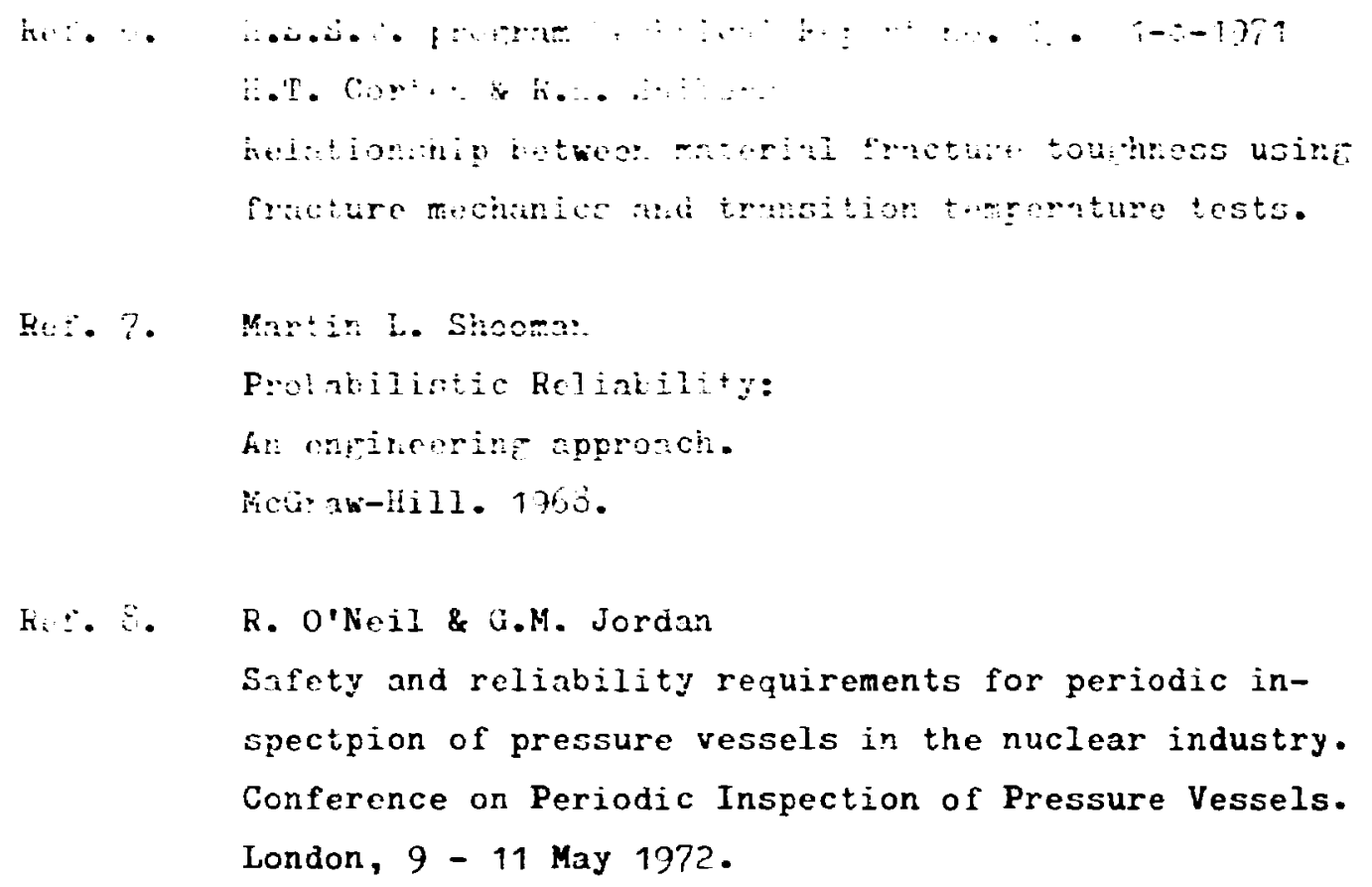

Ref. 9. NEDO 10029

L.C. Hsu

An analytical study on brittle fracture of G.E.-BWR vessels subject to the design basis accident.

June 1969.

Ref. 10. DOCKET 50321-46

Edwin I Hatch Nuclear Plant unit 1.

F.S.A.R. Amend. 17

(Georgia Power Co., Atlanta)

26-6-1972.

Ref. 11. ORNL-4855

Heavy-Section Steel Technology Program.

Semi-Annual Progress Report, ending August 31, 1972.

(Oak Ridge National Lab., Tenn)

April 1973. 


$$
\text { density }
$$

funcioin

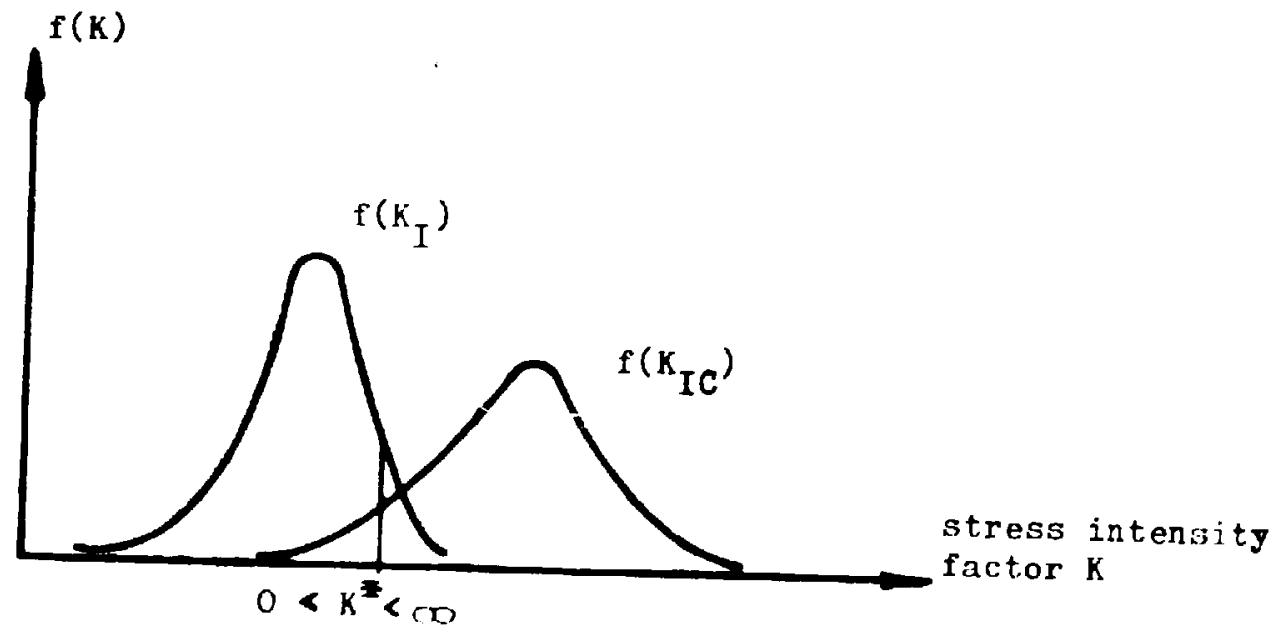

Fig. 1.: Fillig. male 


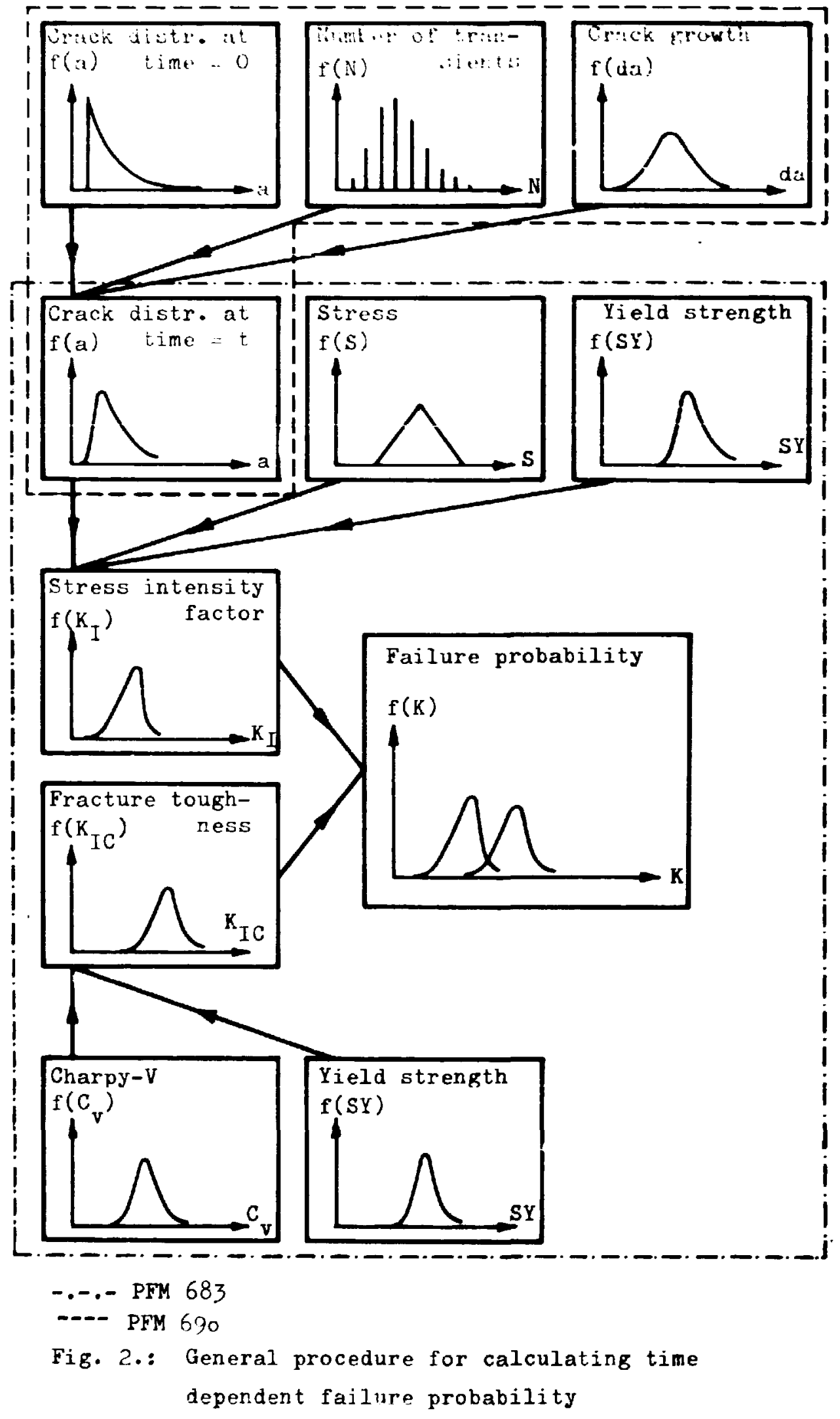




\section{INPUT:}

Initial craci distr. (or single crack)

Crack growth characteristics

Stress distr.

Normal transients

Frequency for abnormal transients

Number of periods

(table $x, f(x)$ or Weibull constants $m, K, x_{0}$

$\left(\right.$ for $\left.f(x)=K\left(x-x_{0}\right)^{m} \exp \left(-\frac{K}{m+1}\left(x-x_{0}\right)^{m+1}\right)\right)$

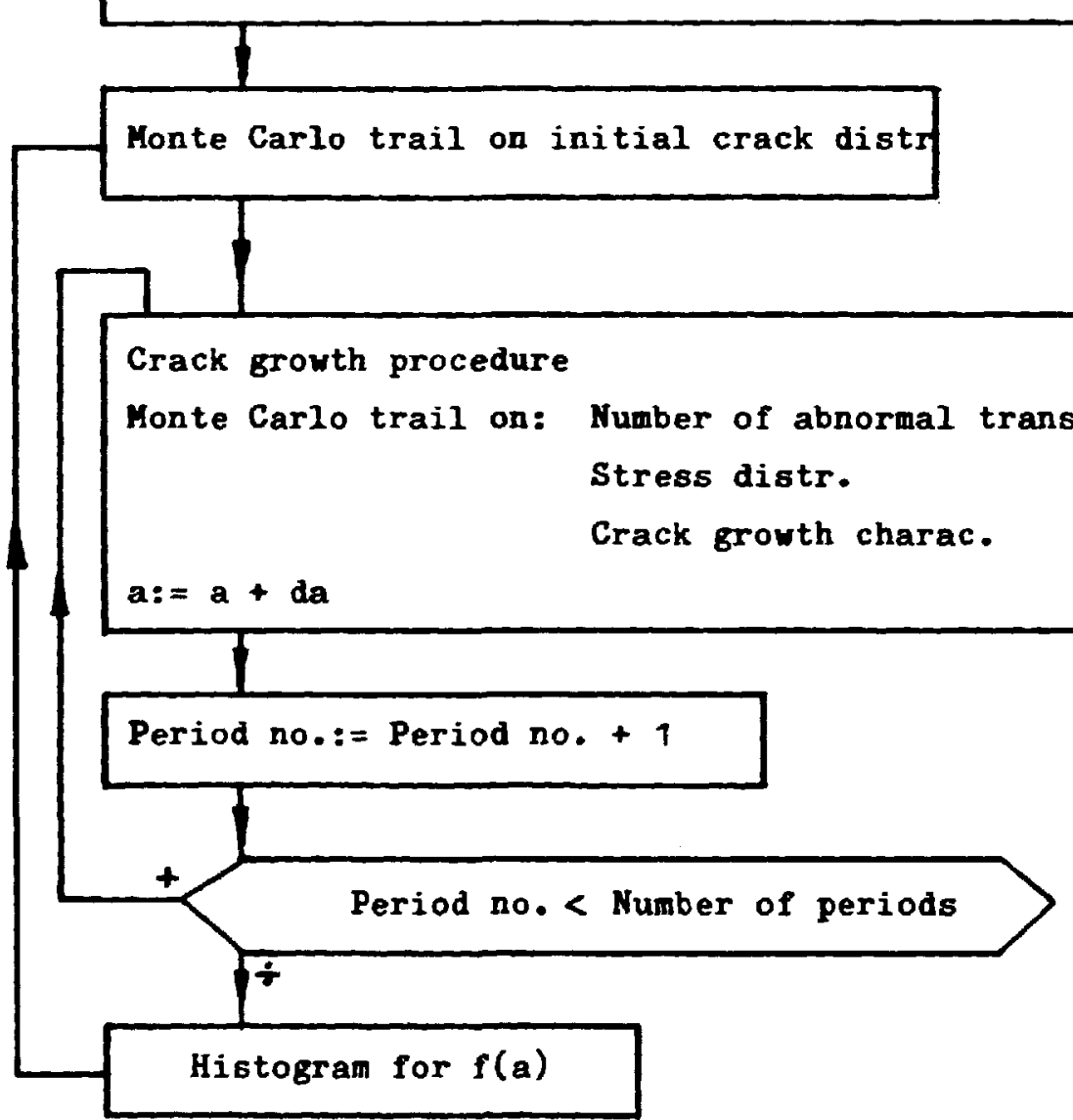

Fig. 3.: Diagram for computer code PFM 690 , which calculates crack growth 


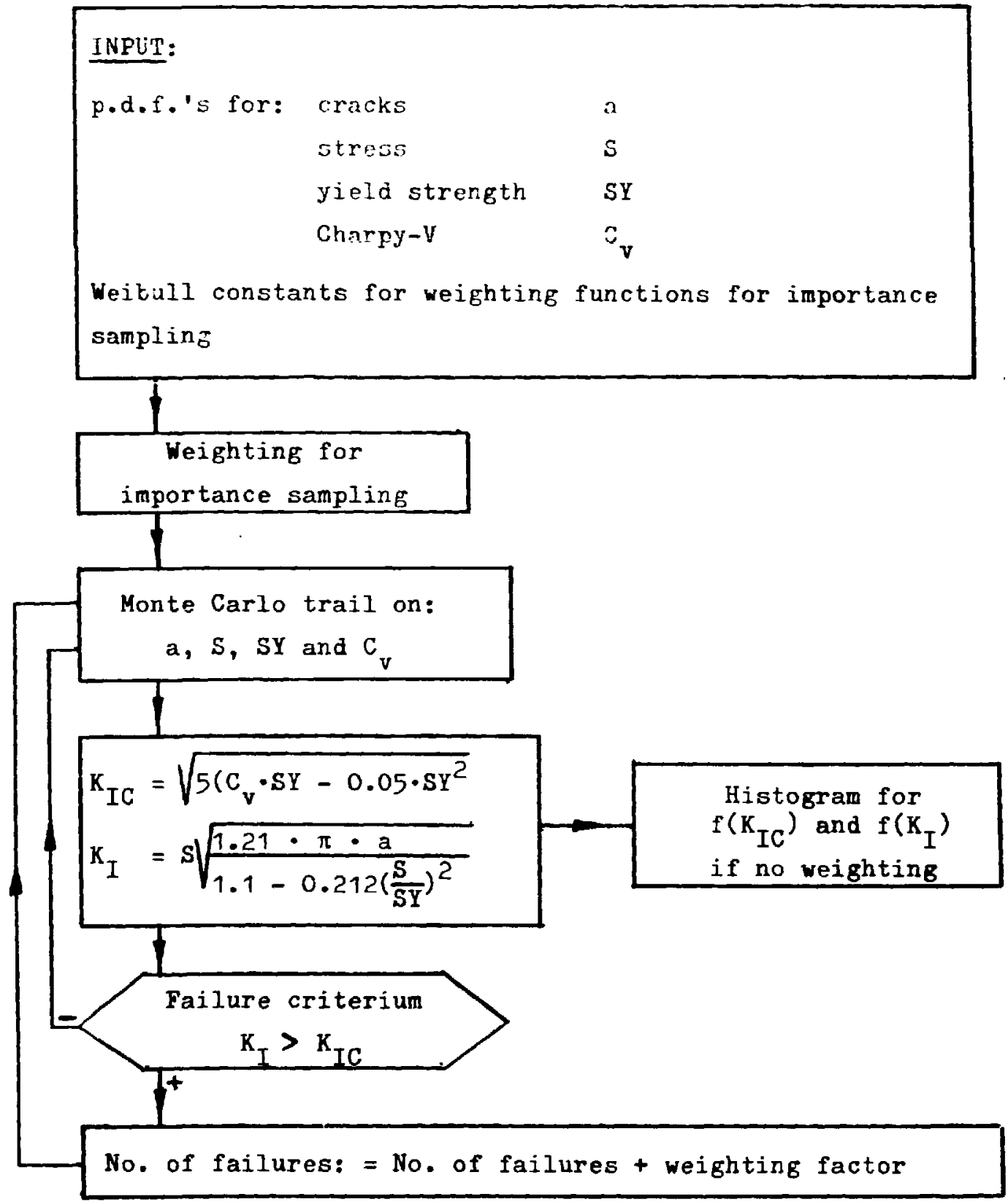

Fig. 4.: Diagram for computer code PFM 683, which calculates

failure probability 


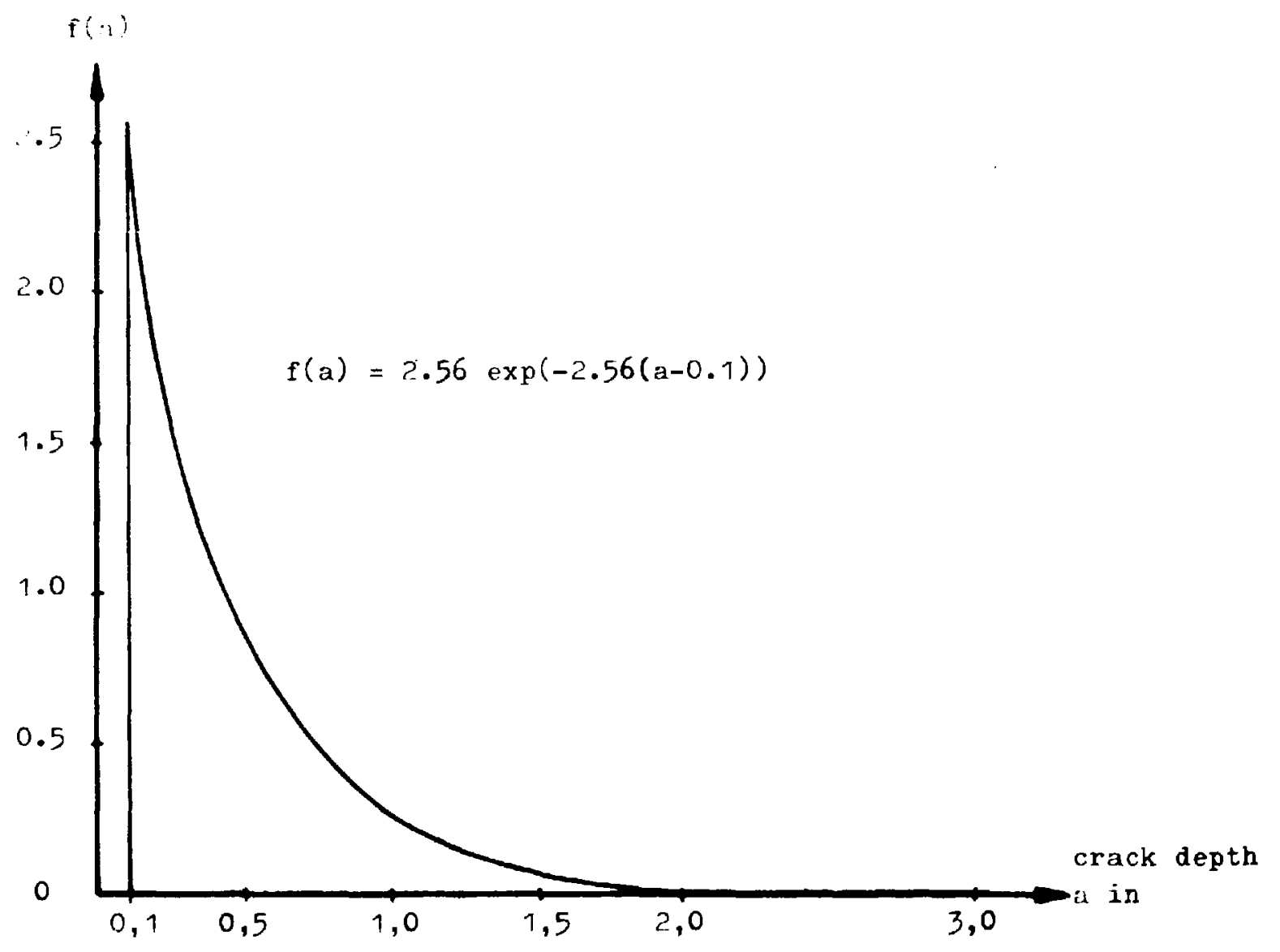

F.g. 5.: Initial crack distribution. 


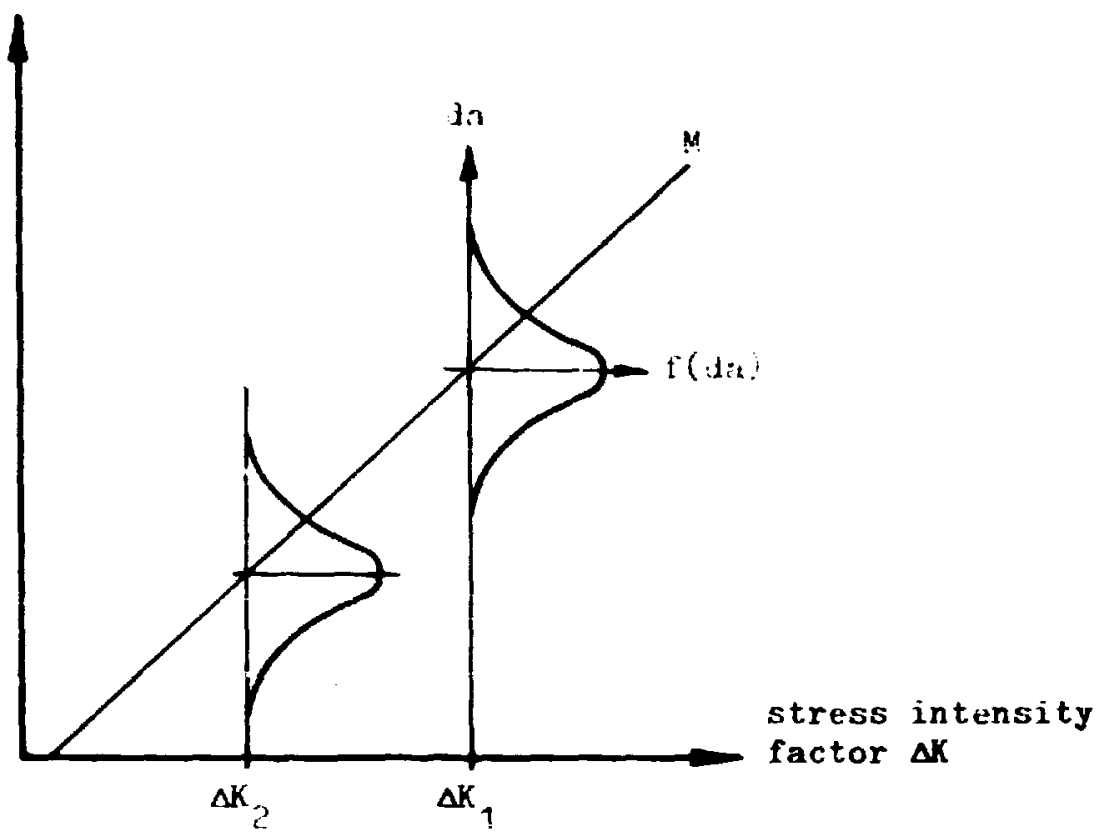

Fig. 6.: Statistical model for crack growth (log-log diagram).

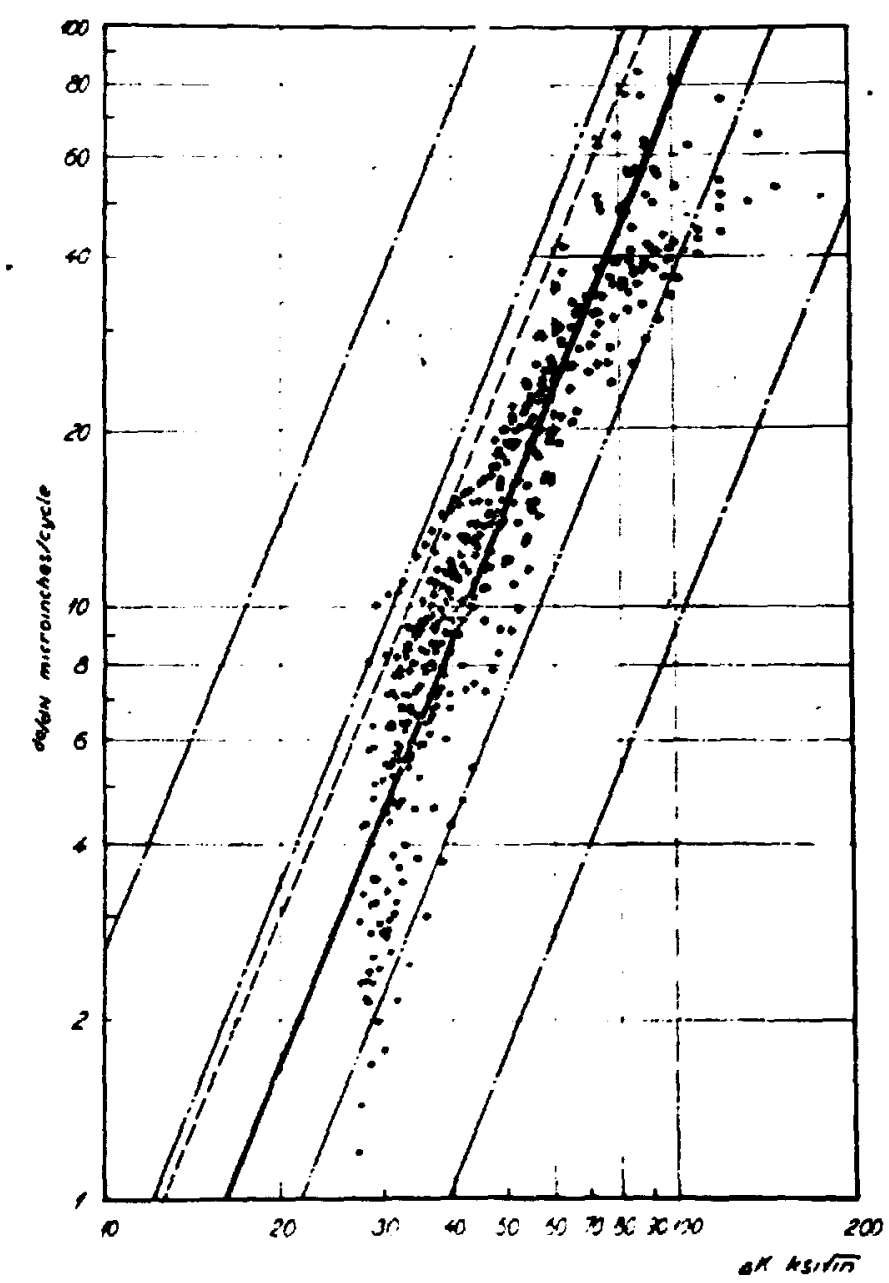

Fig. 7.: Crack growth data for A533B steel (from HSST-program) 
Normal Startup $\left(100^{\circ} \mathrm{F} / \mathrm{Hr}\right) \ldots \ldots \ldots \ldots \ldots \ldots \ldots . . \ldots \ldots$

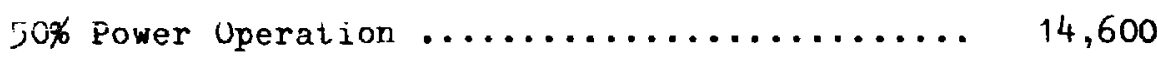

Rod Worth Tests ...................... 400

Loss of Feedwater Heaters

Turbine Trip at 25\% Power ............. 10

Feedwater Heater Bypass .............. 70

Loss of seedwater Pumps ................ 10

Turbine Generator Trip ................. 40

Reactor Overpressure...$\ldots \ldots \ldots \ldots \ldots \ldots \ldots$. 1

Safety Valve Blowdown..$\ldots \ldots \ldots \ldots \ldots \ldots \ldots \ldots$

All other scrams ................... 147

Improper Start of Cold Recirc. Loop .......... 5

Sudden Start of Cold Recirc. Loop ........... 5

Normal Shutdown

$100^{\circ} \mathrm{F} / \mathrm{hr}$ Cooldown $\left(540-375^{\circ} \mathrm{F}\right)$

Shutdown Flooding $\left(375-330^{\circ} \mathrm{F}\right)$

$100^{\circ} \mathrm{F} / \mathrm{hr}$ Cooldown $\left(330-100^{\circ} \mathrm{F}\right) \ldots \ldots \ldots \ldots \ldots . .118$

In addition, the vessel is expected to be subjected to 133 cycles of hydrostatic pressure tests, three of which will be at $125 \%$ of design pressure, and 130 at design pressure.

Fig. 8.: Standard design operating conditions (from. ref. 10 ). 


\begin{tabular}{|l|l|c|c|c|c|}
\hline $\begin{array}{l}\text { Operating } \\
\text { condition }\end{array}$ & Category & $\begin{array}{l}\text { Stress } \\
\text { psi }\end{array}$ & $\begin{array}{l}\text { No. of } \\
\text { cycles } \\
40 \text { years }\end{array}$ & $\begin{array}{c}\text { No. of } \\
\text { cycles } \\
\text { year }\end{array}$ & $\begin{array}{c}\text { No. of } \\
\text { cycles } \\
\text { month }\end{array}$ \\
\hline $\begin{array}{l}\text { Preoperational } \\
\text { hydrostatic } \\
\text { test to 125\% } \\
\text { of design press }\end{array}$ & Normal & 33.000 & 3 prior to initial start-up \\
\hline $\begin{array}{l}\text { Start-up/ } \\
\text { Shutdown }\end{array}$ & Normal & 26.000 & 240 & 6 & - \\
\hline $\begin{array}{l}\text { Hydrostatic } \\
\text { test to design } \\
\text { press }\end{array}$ & Normal & 27.000 & 120 & 3 & - \\
\hline $\begin{array}{l}\text { Scram - } \\
\text { Hot Standby } \\
\text { - Full Power }\end{array}$ & Abnormal & 26.000 & 240 & 6 & 0.5 \\
\hline $\begin{array}{l}\text { Scram - } \\
\text { Shutdown - } \\
\text { start-up }\end{array}$ & Abnormal & 30.000 & 60 & 1.5 & 0.125 \\
\hline $\begin{array}{l}\text { Loss of re- } \\
\text { circulation } \\
\text { flow }\end{array}$ & Abnormal & 28.000 & 5 & 0.125 & 0.01 \\
\hline Blow down & Abnormal & 27.000 & 2 & 0.05 & 0.0042 \\
\hline
\end{tabular}

Fig. 9.: Condensed scheme of stress transients. 


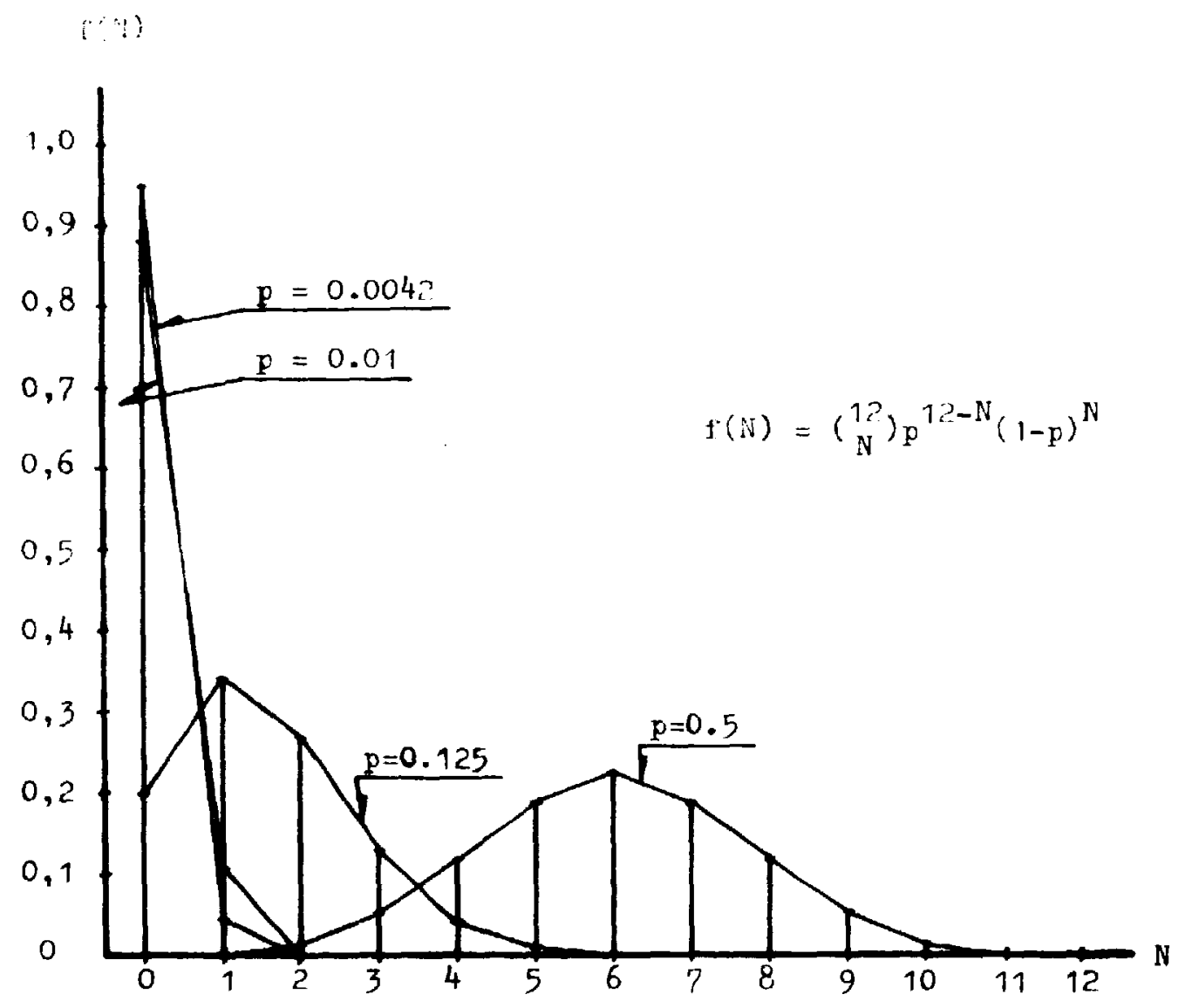

Fig. 10.: Probability density function for number of abnormal transients. 


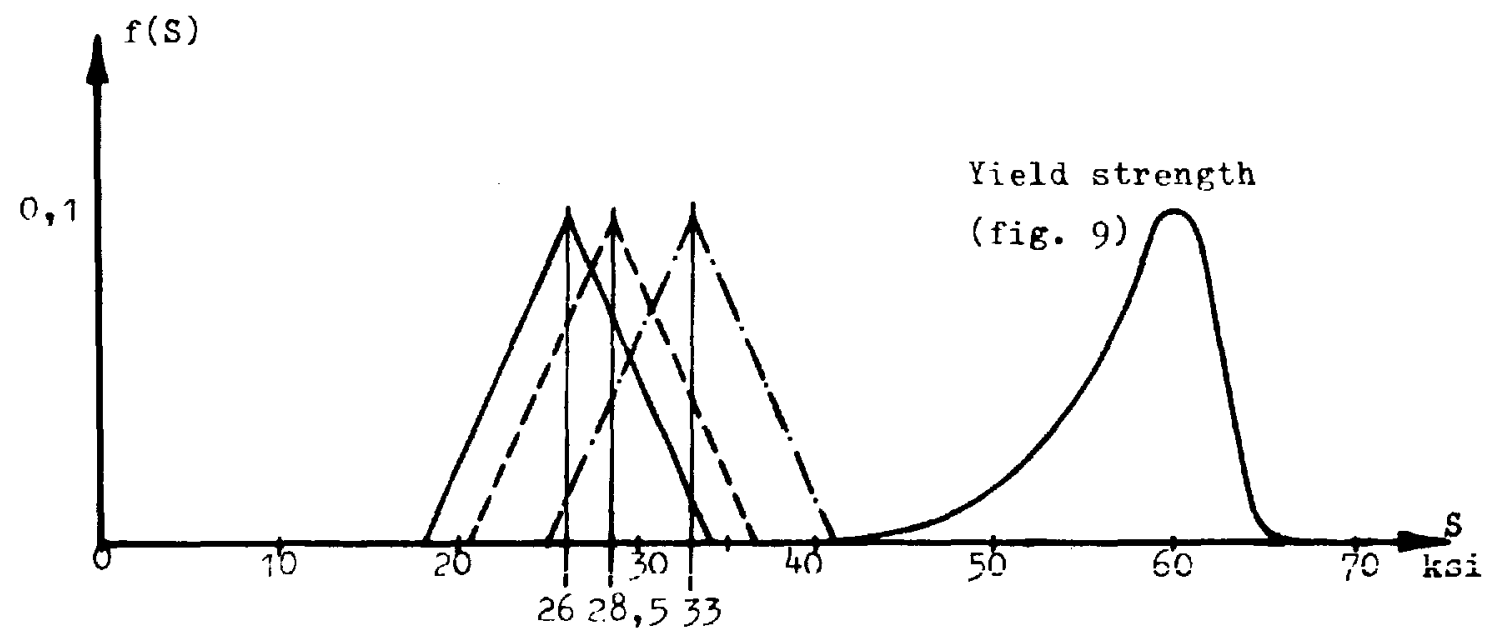

ASME sec. II I

-.-- DIN

-.-.- Preoperitional hydrotest

Fig. 11.: Probability density function for stresses 


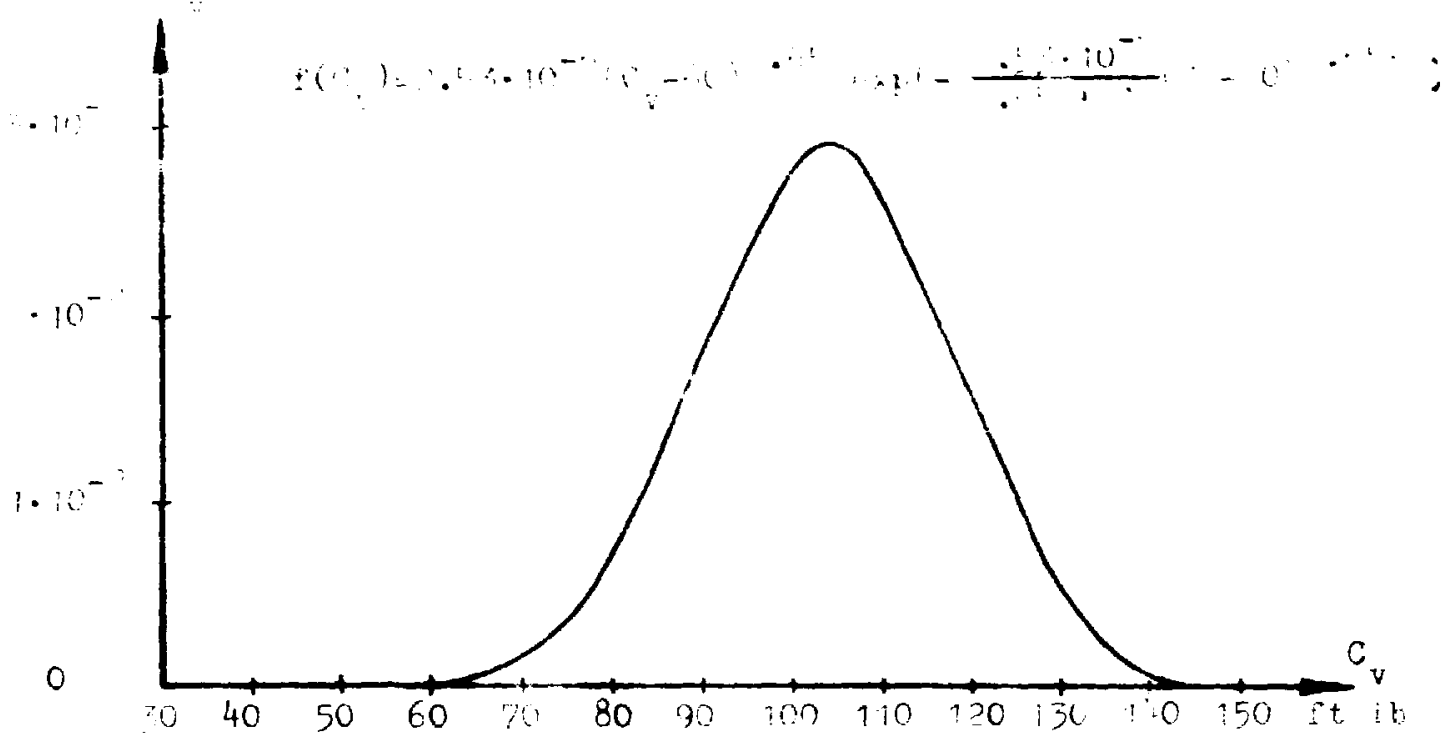

Fig.12.: Probability denrity function for Charpy-V.

Published data from HSST-program.

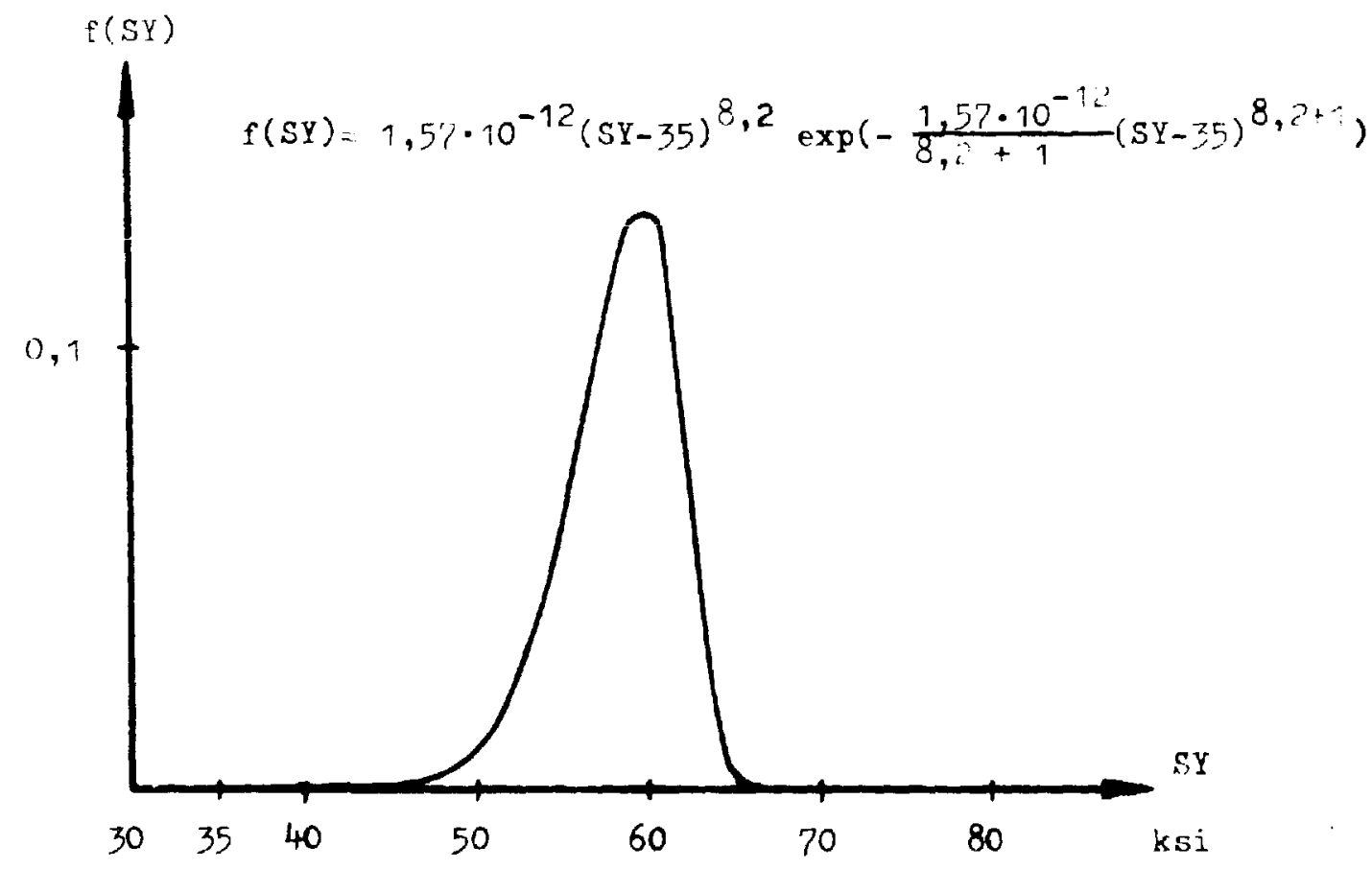

Fig.13.: Probability density function.

Published data from HSST-program. 


\begin{tabular}{|c|c|c|c|}
\hline $\begin{array}{l}\text { Initiai } \\
\text { crack ir. }\end{array}$ & $\begin{array}{c}\text { Statistical } \\
\text { condition }\end{array}$ & $\begin{array}{c}\text { Mesulting crack } \\
\text { after 10 yeari } \\
\text { of operatior }\end{array}$ & $\begin{array}{c}\text { Resultinf crack } \\
\text { after 40 jears } \\
\text { of operation }\end{array}$ \\
\hline 1.0 & Most frob. & 1.01 & 1.025 \\
\cline { 2 - 5 } & Max. & 1.02 & 1.045 \\
\hline \multirow{3}{*}{2.0} & Most prob. & 2.015 & 2.055 \\
\cline { 2 - 5 } & Max. & 2.045 & 2.095 \\
\hline & Most prob. & 3.02 & 3.09 \\
\hline
\end{tabular}
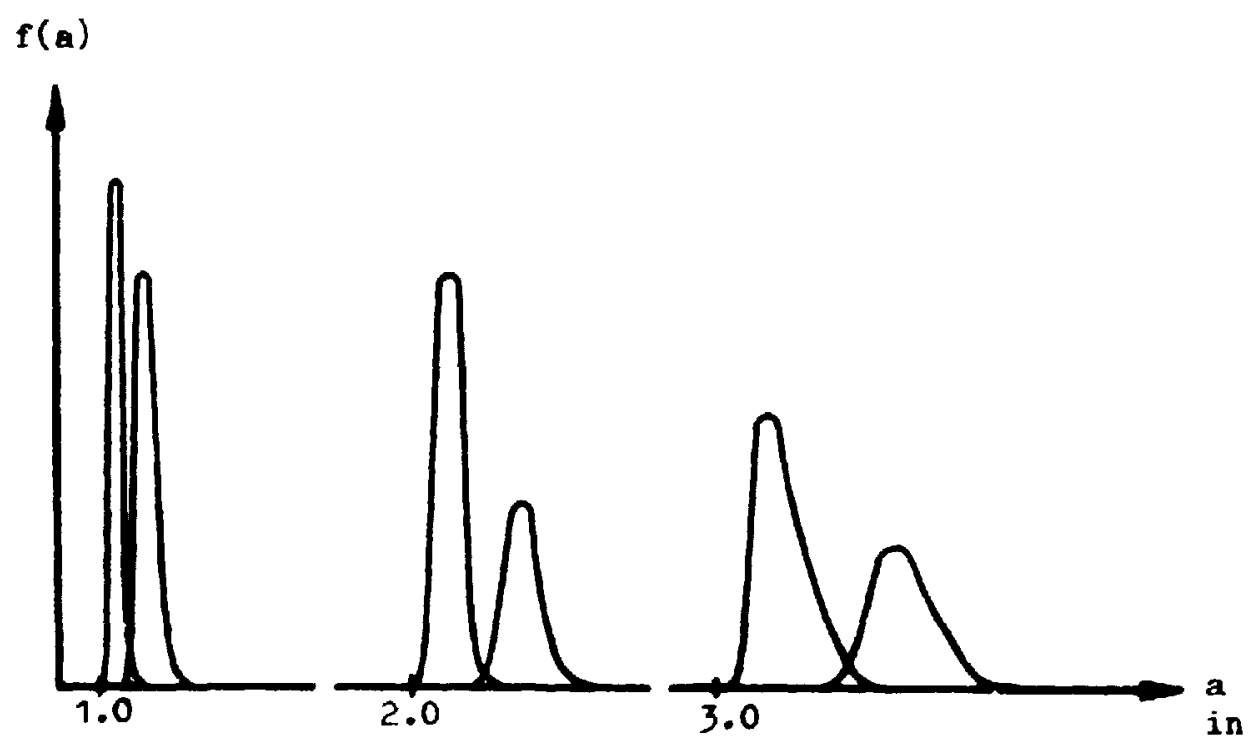

Fig. 14.: Statistical crack growth for 1 ', $2^{\prime \prime}$ and $3^{\prime \prime}$ cracks after 10 and 40 years of operation 


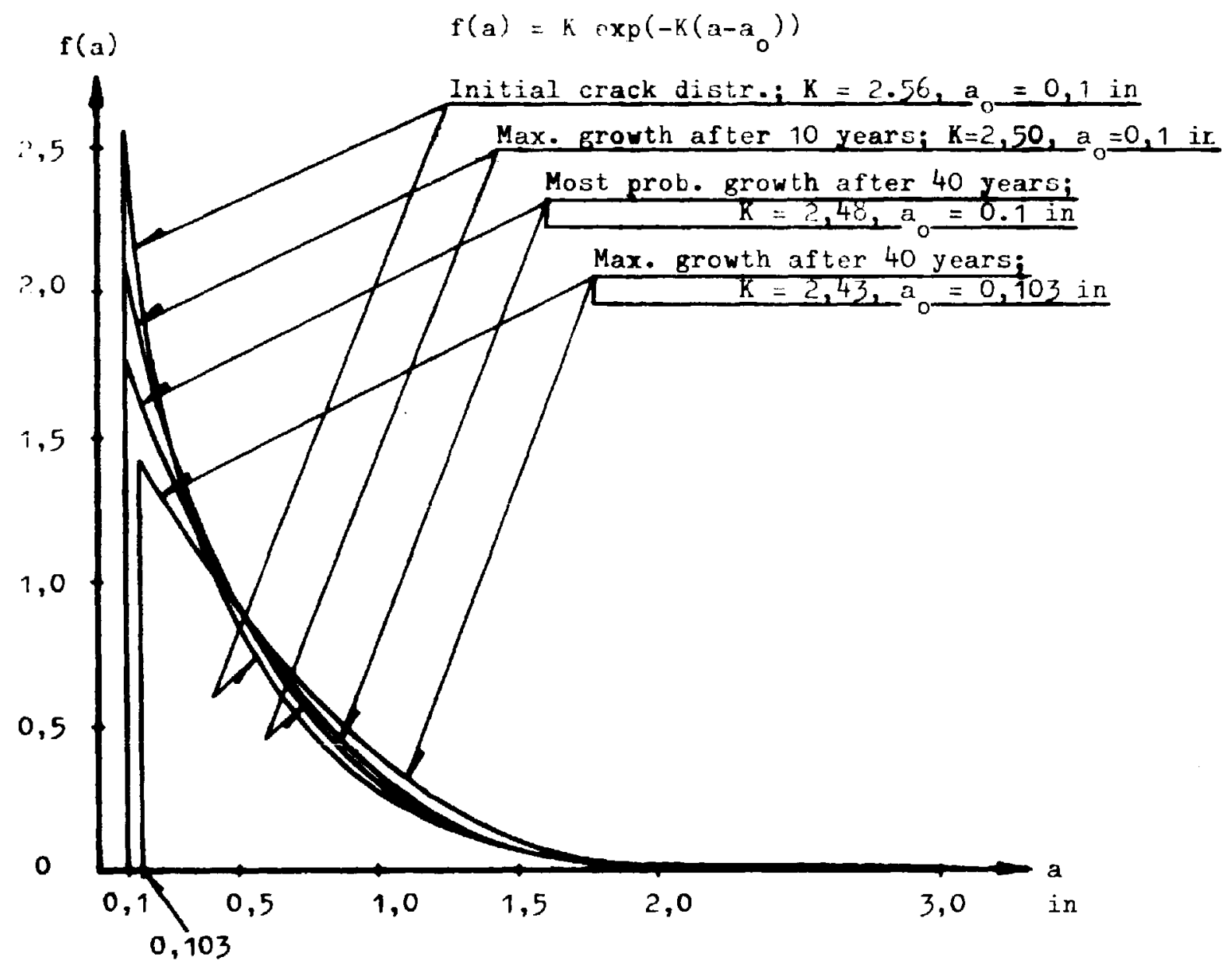

Fig. 15.: Crack distribution at 0,10 and 40 years of operation. Evaluated on basis of fig. 13. 


\begin{tabular}{|c|c|c|c|}
\hline $\begin{array}{c}\text { Years of } \\
\text { operation }\end{array}$ & $\begin{array}{c}\text { Mean stress } \\
\mathrm{Ksi}\end{array}$ & Failure probability & $\begin{array}{c}95 \% \text { confidence } \\
\text { limits }\end{array}$ \\
\hline 0 & 26.0 & $1.24 \times 10^{-8}$ & $\left.\begin{array}{l}0.90 \\
1.58\end{array}\right\} \times 10^{-8}$ \\
\hline 10 & 26.0 & $1.89 \times 10^{-8}$ & $\left.\begin{array}{l}1.34 \\
2.45\end{array}\right\} \times 10^{-8}$ \\
\hline 40 & 26.0 & $2.45 \times 10^{-8}$ & $\left.\begin{array}{l}1.73 \\
3.21\end{array}\right\} \times 10^{-8}$ \\
\hline 0 & 33.0 & $178 \times 10^{-8}$ & $\left.\begin{array}{l}163 \\
194\end{array}\right\} \times 10^{-8}$ \\
\hline 0 & 28.5 & $7.8 \times 10^{-8}$ & $\left.\begin{array}{l}7.3 \\
8.3\end{array}\right\} \times 10^{-8}$ \\
\hline
\end{tabular}

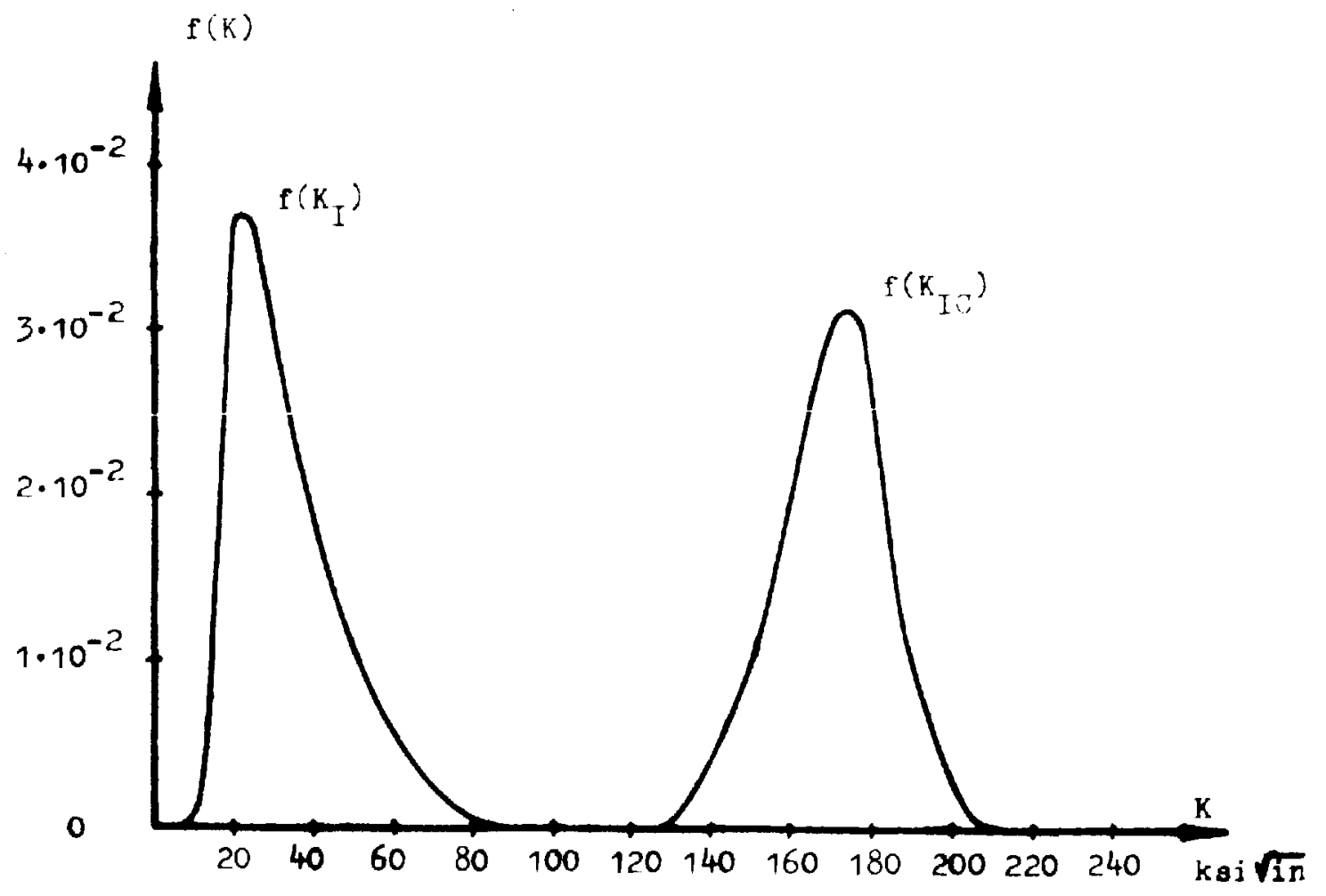

Fig. 16. Result of failure calculations 